\title{
Homogeneous Enzyme-Linked Binding Assay Mediated by the Interaction of Avidin with Biotin: Mistletoe Lectin I Assay
}

\author{
Insook Rhee Paeng," Eun Ah Lee, and Hỵun Sook Kim \\ Department of Chemistry. Seoul Homen's Lniversin, Seoul 139-774, Korea \\ Received September 17, 2003
}

\begin{abstract}
We have examined the feasibility of using the specific interaction between mistletoe lectin I (ML I) and $\beta$-Dgalactose instead of the anti-ML I antibody in developing a homogeneous type competitive binding assay for ML I. We also have examined the feasibility of adapting the biotin/avidin mediated homogeneous assay for this ș'stem. Alkaline phosphatase (AKP) was employ'ed as a single substrate enzy'me label. The dose-response curve shows a detection range of $1-25 \mu \mathrm{g} / \mathrm{mL}$ and a linear response with a correlation coefficient of 0.99 . To demonstrate the analytical utility of this method. $10 \mu \mathrm{g} / \mathrm{mL}$ of $\mathrm{ML}$ I was spiked into distilled water. The results show that the mean recovery was $10.03 \mu \mathrm{g} / \mathrm{mL}$ with an $\mathrm{SD}$ of 0.18 . The difference between the spiked value and the mean recovery was $0.03 \mu \mathrm{g} / \mathrm{mL}$. with a relative error of 0.3 and $1.6 \%$ of RSD.
\end{abstract}

Key Words : ELBA, Avidin/Biotin, ML I. Homogeneous assay

\section{Introduction}

Aqueous extracts of mistletoe are widely used in cancer prevention and as an adjuvant therapy' in cancer treatment. ${ }^{1-3}$ Their therapeutic activity ${ }^{4}$ is mainly due to the immunostimulating and immunomodulating properties of one of the group of mistletoe lectins (ML), ML I. Mistletoe lectins type I. II and III consist of two subunits. a cytotoxic A-chain and a sugar binding B-chain. linked by disulfides. ${ }^{5-7}$ Among the three types of ML. ML I is the major active constituent of mistletoe extracts and the $\beta$-D-galactose (gal) grouprecognizing one. whereas ML II and ML III are specific to $\mathrm{N}$-acetylgalactosamine group binding. ${ }^{\S}$ Quantitative deternination of mistletoe lectins. especially ML I. has been examined using the enzr'me-linked immunosorbent assay (ELISA) and the enz̧me-linked lectin assay (ELLA) ${ }^{10}$ by using an anti-ML I antibody: Both methods are heterogeneous arrangements. which are too slow because of the timeconsuming washing steps to separate bound and free enzyme labels. Also. another disadvantage of these methods' is the response of lectins. ML I. II. and III to the anti-ML I antibody used for the ML I assay. The homogeneous type assay's. such as the enzyme-multiplied immunoassay' teclunique (EMIT). ${ }^{11}$ are more rapid because there is no need for separation steps. and they are. additionally. amenable to automation.

In the present work we examined the feasibility of using the specific interaction ML I with gal instead of the anti-ML I antibody in developing a homogeneous type competitive binding assay for ML I. We examined the feasibility of adapting the biotin/avidin mediated ${ }^{12-14}$ homogeneous assay method to a new analyte system. Alkaline phosphatase (AKP), a single substrate enzy'me was employ'ed to measure the enzyme activity at $405 \mathrm{~nm}$. The proposed method

\footnotetext{
To whon correspondence should be addressed. Tel: +82-2-970-
} 5657; Fax: +82-2-970-5972: e-mail: ippaengàswu.ackr utilized AKP-biotin conjugate as a signal generator and an avidin-gal conjugate as a signal modulator in the solution phase AKP-biotin conjugate was inhibited in solution by the avidin-gal conjugate due to the recognition reaction of the avidin and biotin. In the presence of a gal-specific binder. ML I, the enzymatic activity of the conjugate was regained in an amount proportional to the concentration of ML I. since the enzy'me inactivation by the sterical hindering of the binding between AKP-biotin and avidin-gal was released due to the binding of the ML I to the avidin-gal conjugate. Homogeneous competitive binding assay for ML I mediated by the avidin/biotin interaction was optimized and the doseresponse behaviors were examined.

\section{Experimental Section}

Enz'matic activities were measured with a Gilford Stassar-III spectrophotometer equipped with a vacuumoperated sampling system and temperature-controlled cuvette. This spectrophotometer was connected to a Syva CP-5000 EMIT Clinical Processor for automatically setting the reading intervals and recording the absorbance values.

AKP from bovine intestinal mucosa. bovine serum albumin (BSA). $N$-hy'droxysuccinimidobiotin (NHS-biotin). avidin from egg white. and gal were obtained from Sigma (St. Louis. MO. USA). ML I was purchased from the Institute of Phytochemistry. University of Witten/Herdecke. Germany. Deionized water was used to prepare all buffers.

Preparation of AKP-biotin conjugates. AKP-biotin conjugate was prepared by reacting AKP with different amounts of NHS-biotin. The required amount of NHS-biotin dissolved in dimethylformanide (DMF) was added to 500 $\mu \mathrm{L}$ of coupling buffer containing a given amount of 200 units for AKP. The coupling buffer was $0.05 \mathrm{M}$ sodium carbonate. $\mathrm{pH}$ 9.0. The reaction was nun for 24 lor at $4{ }^{\circ} \mathrm{C}$ under stirring. After reaction, the conjugate was dialyzed against $0.05 \mathrm{M}$ Tris- $\mathrm{HCl} . \mathrm{pH} 7.8$, and diluted to a final 
volume of $2.0 \mathrm{~mL}$ with the dialysis buffer. The resulting enzyme conjugates were characterized by their residual activities and percent inhibition induced by an excess amount of avidin. All conjugates were kept at $4{ }^{\circ} \mathrm{C}$ until the additions of reagents for activity measurements.

Preparation of avidin-galactose conjugates. Three mg of avidin were dissolved in $2.5 \mathrm{~mL}$ of coupling buffer. 0.05 $\mathrm{M}$ sodium carbonate. $\mathrm{pH} 9.2$. To protect the active site of avidin, $1 \mathrm{mg}$ of 2 -iminobiotin dissolved in $100 \mu \mathrm{L}$ of DMF was added to the avidin solution. The required anount of $\beta$ $D$-galactopyranosy lphenyl isothiocyanate was added to each $500 \mu \mathrm{L}$ of the avidin/iminobiotin solution. The coupling reaction was run for $24 \mathrm{hr}$ at $4{ }^{\circ} \mathrm{C}$ under stirring. The resulting avidin-gal conjugates were dialyzed against $0.05 \mathrm{M}$ Tris- $\mathrm{HCl}$. $\mathrm{pH} 7.8$. and diluted to a final volume of $2.0 \mathrm{~mL}$ with the dialysis buffer.

Determination of enzymatic activity and percentage inhibition. The activity of AKP-biotin conjugates was determined by measuring the rate of appearance of $p$ nitrophenol, measured by the change in absorbance at 405 num per unit time. The assay involves addition of $100 \mu \mathrm{L}$ of $p$-nitrophenyl phosphate $(10 \mathrm{mM})$ and $100 \mu \mathrm{L}$ of AKPbiotin conjugate to a tube containing $800 \mu \mathrm{L}$ of assay buffer. For each assay. after mixing and agitation $(1-2 \mathrm{~s})$, the reaction mixture was aspirated into the thermostatic flow cell of the spectrophotometer. The absorbance of the misture in each tube was read over a l-min period $(\Delta \mathrm{A} / \mathrm{min})$ after an initial 10 -s delay for AKP-biotin conjugates. To deternine the percent inhibition value for each conjugate, $100 \mu \mathrm{L}$ of assay buffer was replaced by $100 \mu \mathrm{L}$ of avidin or avidin-gal $(10 \mu \mathrm{g} / \mathrm{mL})$ prepared in assay buffer. In addition. conjugates were first incubated with avidin or avidin-gal for $10 \mathrm{~min}$ before subsequent addition of substrate solution. The reversed percent inhibition was determined by incubating $100 \mu \mathrm{L}$ of each avidin-gal conjugate $(5 \mu \mathrm{g} / \mathrm{mL})$ with $100 \mu \mathrm{L}$ ML I $(10 \mu \mathrm{g} / \mathrm{mL})$ for $10 \mathrm{~min}$, and with the addition $100 \mu \mathrm{L}$ AKP-biotin 3 ( 1 : 100 dilution; 0.1 units), and then incubating the mixture for $10 \mathrm{~min}$. The working assay buffer for AKP-biotin conjugate was $0.05 \mathrm{M}$ sodium carbonate $(\mathrm{pH}$ 9.5). containing $0.01 \%(\mathrm{w} / \mathrm{v}) \mathrm{NaN}_{3}$ and $0.01 \%(\mathrm{w} / \mathrm{v})$ gelatin. And dilutions of avidin-gal conjugates. binders. standards. and sample solutions were made using $0.05 \mathrm{M}$ Tris $-\mathrm{HCl}(\mathrm{pH}$ 7.8). containing $0.01 \%(\mathrm{w} / \mathrm{v}) \mathrm{NaN}_{3} .0 .5 \%(\mathrm{w} / \mathrm{v})$ Tween 20 and $0.01 \%(\mathrm{w} / \mathrm{v})$ gelatin.

Association kinetic study. The rate of binding between AKP-biotin and avidin-gal conjugates was measured by mixing $100 \mu \mathrm{L}$ AKP-biotin ( 1 : 100 dilution) with $100 \mu \mathrm{L}$ of axidin-gal $(10 \mu \mathrm{g} / \mathrm{mL})$ and by incubating the mixture for varying periods of time. The kinetics of association between axidin-gal and ML I was studied by first incubating a mixture of $100 \mu \mathrm{L}$ of aridin-gal $6(5 \mu \mathrm{g} / \mathrm{mL})$ and $100 \mu \mathrm{L}$ of ML I $(10 \mu \mathrm{g} / \mathrm{mL})$ for varying periods of time. adding $100 \mu \mathrm{L}$ of AKP-biotin 3 ( $1: 100$ dilution) and incubating the mixture for $10 \mathrm{~min}$. After incubation, the enzymatic activity was determined by adding the substrate solution as outlined above.

Dilution curve of avidin-gal conjugate. One hundred $\mu \mathrm{L}$ of solutions containing different anounts of avidin-gal6 were incubated with $100 \mu \mathrm{L}$ AKP-biotin3 (1 : 100 dilution) and $700 \mu \mathrm{L}$ of assay buffer for $10 \mathrm{~min}$. The substrate was then added and enzymatic activity was measured as described above. A dilution curve for avidin-gal6 was prepared by plotting percent inhibition ws the amount of avidin-gal6 used.

Dose-response curves. For a dose-response curve for ML I. AKP-biotin 3 and avidin-gal6 were employed. $100 \mu \mathrm{L}$ of solutions containing different amounts of ML I $(100 \mu \mathrm{L})$ were incubated with $100 \mu \mathrm{L}$ of avidin-gal 6 and $600 \mu \mathrm{L}$ of assay buffer for $10 \mathrm{~min}$. After adding $100 \mu \mathrm{L}$ of AKPbiotin 3 conjugate (1:100 dilution). each misture was incubated for an additional $10 \mathrm{~min}$ period. The enzymatic activity was measured as outlined above

\section{Results and Discussion}

In the design of the homogeneous enzyme-linked binding assay (ELBA), the properties of the enzyme conjugate used exert an important effect on analytical performance. The enzyme conjugate in the homogeneous assay must be inhibited by an excess of binder in mixture and still possess high enzymatic activity. Thus. various AKP-biotin conjugates were prepared by reacting AKP with different molar ratios of NHS-biotin. Table 1 summarizes the characteristics of AKP-biotin conjugates. As can be seen. the residual activity decreased with an increasing initial molar ratio of biotin/ AKP. whereas the percent inhibition of enzyme increased with an initial molar ratio up to 2250 (biotin/AKP) and started to decrease due to a given excess of avidin in all cases. These observations show that the number of biotins attached to the enzyme molecule increased with a higher biotin/enzyme ratio. However. the inhibition was reversed when too much biotin was attached (AKP-biotint). Therefore, on the basis of the residual activity and maximum percentage inhibition, AKP-biotin 3 was chosen for use in these subsequent homogeneous binding assay studies.

In the homogeneous ELBA for ML I mediated by avidin/ biotin interaction, it was additionally necessary to synthesize avidin-gal conjugates. Here, the binding ability of avidin-gal to both AKP-biotin and ML I affects the detection capabilities of the assay. To accomplish a sensitive homogeneous assay, avidin-gal conjugates must retain high binding affinity toward biotin in AKP-biotin. And the observed inhibition needs to be reversed when ML I binds the gal attached to

Table 1. Characteristics of AKP-Biotin Conjugates

\begin{tabular}{lccc}
\hline Conjugates & $\begin{array}{c}\text { Initial biotinl } \\
\text { AKP molar ratio }\end{array}$ & $\begin{array}{c}\text { \% Residual } \\
\text { activity }^{\sigma}\end{array}$ & $\begin{array}{c}\text { \% Inhibition } \\
\text { by avidin }\end{array}$ \\
\hline AKP-Biotinl & 0 & 100 & 0 \\
AKP-Biotin2 & 2000 & 70 & 72 \\
AKP-Biotin3 & 2250 & 65 & 76 \\
AKP-Biotin4 & 2500 & 64 & 74 \\
\hline
\end{tabular}

"Percent residual activity' was calculated by comparing the activities of the conjugates to the initial activity of the unconjugated enzyme. ${ }^{b}$ Percent inlibition was deternined by using $1: 100$ dilutions of the conjugates and $10 \mu \mathrm{g}$ Avidin. 


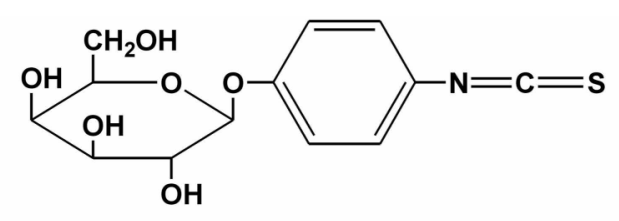

$p$-isothiocyanatophenyl $\beta$-D-galactopyranose

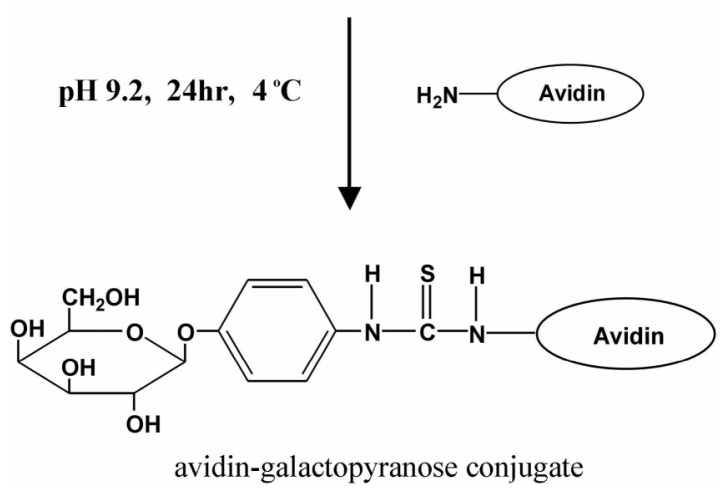

Figure 1. Rasetion sequence used for preparing avidin-galactopyranose conjugate.

avidin. In this work, several avidin-gal conjugates were prepared by varying initial molar ratios in the conjugation reaction mixture, according to the reaction scheme shown in Figure 1. A 100-fold excess of 2 -imminobiotin to avidin was used as described in the experimental section to prevent the attachment of galactose to the binding site of avidin during conjugation. And 2-immunobiotin can be removed readily during the dialysis process of avidin-gal conjugates. Table 2 summarizes the characteristics of the avidin-gal conjugates.

The percentage inhibition induced by avidin-gal and the reversed inhibition by $\mathrm{Ml}$. I were estimated by using the AKP-biotin 3 conjugate. It decreased due to the ability of the avidin-gal conjugate to inhibit the AKP-biotin conjugate, when the initial molar ratio of gal/avidin increased. The more gal attached to avidin, the more steric hindrance occurred on binding of avidin to the AKP-biotin conjugate. However, the reversed extent of the observed inhibition by a given excess ML I tended to increase as the initial molar ratio of gal/avidin increased. since Avidin-gal6 exhibits a high inhibitory effect, up to $59 \%$, and more importantly,

Table 2. Characteristics of Avidin-galctose Conjugates

\begin{tabular}{lccc}
\hline Conjugates & $\begin{array}{c}\text { Ifjitial gal/ } \\
\text { avidit molar } \\
\text { ratio }\end{array}$ & $\begin{array}{c}\% \text { Inhibition }^{2} \\
\text { (without MI.) }\end{array}$ & $\begin{array}{c}\% \text { Inhibition } \\
\text { (with MI.) }\end{array}$ \\
\hline Avidin-gal] & 0 & 100 & 100 \\
Avidit)-gal2 & 50 & 93 & 79 \\
Avidin-gal3 & 100 & 86 & 66 \\
Avidin-gal4 & 150 & 81 & 62 \\
Avidin-gal5 & 250 & 80 & 53 \\
Avidin-gal6 & 300 & 59 & 16 \\
Avidin-gal7 & 350 & 55 & 23
\end{tabular}

"Jercent inhibition was determined by using I: 100 dilution of AKPbiotin 3 and $5 \mu \mathrm{g}$ of each Avidin-gal conjugates. "Reversed percent inhibition was determined by using $10 \mu \mathrm{g}$ ol . VL.

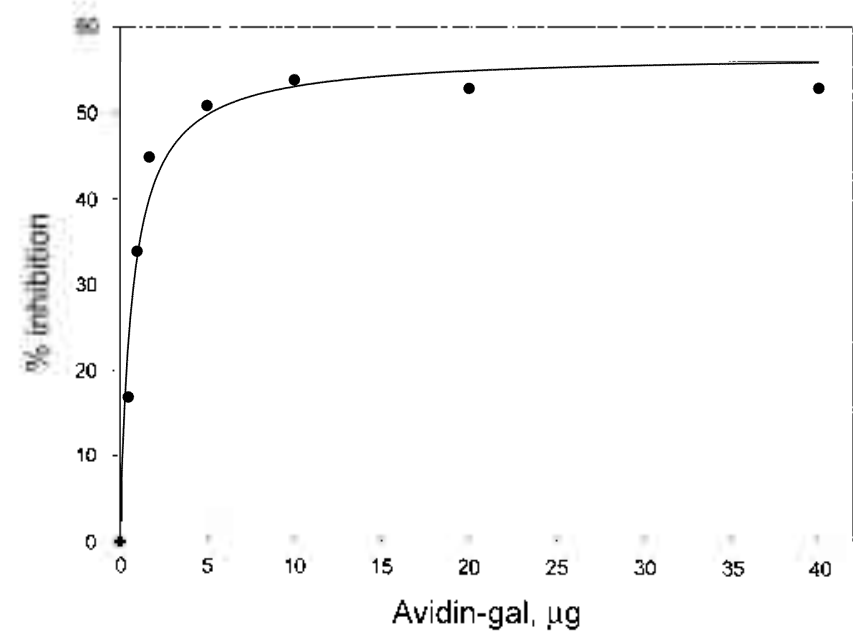

Figure 2. Filect of varying the levels of avidin-galf on the inhibition of $\triangle \mathrm{KP}$-biotin? $(0.1$ units).

reverses the observed inhibition up to $84 \%$ with an excess MI. 1. The degree of such activity modulator is sufficiently high for use in homogeneous type assay arrangements. Thus, avidin-gal 6 was chosen as the signal modulator.

This assaty involved two types of binding interactions: AKP-biotin with avidin-gal, and avidin-gal with ML, I. Information on their association kinetics was recuired to determine the optimal incubation periods for this assay. More than $95 \%$ of the maximum inhibition was achieved within 10 min of incubation in both cases. Thus, for the subsequent experiments, an incubation period of 10 min was chosen for each step.

Binder dilution studies were performed to determine the optimum concentration of binder for the homogeneous assay. A binder dilution curve was prepared for different amounts of avidin-gal6 incubated with a fixed amount of AKP-biotin3 (Figure 2), As shown in Figure 2, as the amount of avidin-gal increases in the assay mixture, the extent of inhibition increases. This figure shows that the use of avidis-gal6 in the range of $1-2 \mu \mathrm{g}$ provided more than $60 \%$

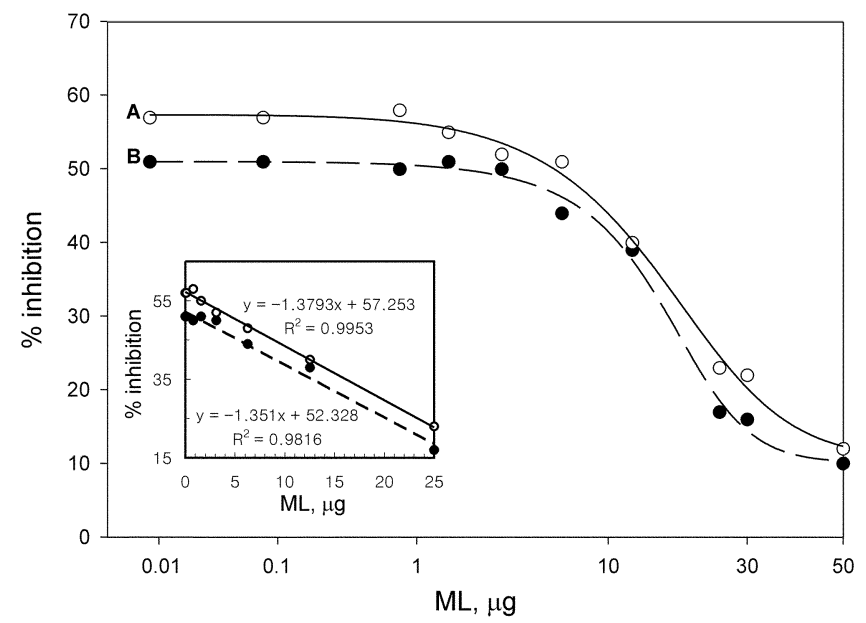

Figure 3. Dose-response curves for ML I on the inhibition of $\triangle \mathrm{KP}$ hiotin3 conjugate $(0.1$ units): (A) I $\mu g$ avidin-gal6 (C): (B) $0.67 \mu$ g avidin-gal6 $(\bullet)$ : insert graph was calibration curves for Ml. I with avidin-gallo conjugale. 
of the maximum inlibition for the AKP-biotin 3 conjugate.

Under the optimized conditions. a competitive dose-response curve for ML I was constructed by plotting percentage inhibition vs. the anount of ML I in the standards (Figure 3). Figure 3(A) and 3(B) were obtained from two different amounts ( $1 \mu \mathrm{g}$ and $0.67 \mu \mathrm{g}$. respectively) of avidin-gal conjugate. It is known that the characteristics (detection limit. effective detection range, etc.) of the dose-response curve are affected by the ratio of binder/enzyme conjugate employed in the assay mixture ${ }^{15-17}$ The intrinsic detection capability of an assay system is almost completely dictated by the binding ability of the binder system. The proposed biotin-avidin mediated assay involves two different binder sy stents; avidin-biotin and ML I-gal systems. In this case, the detection ability of the assay system was influenced by the activity that included the weaker binder system: i.e. the ML Igal system. The curves show a steepness over a detection range ( $1-25 \mu \mathrm{g} / \mathrm{mL}$ ). Also. the inset shows the calibration curves for ML I. including good linearity with a correlation coefficient of 0.9953 (A) and 0.9816 (B), respectively.

Aqueous mistletoe extracts ${ }^{18}$ are used in cancer prevention and as an adjuvant therapy in cancer treatment. Thus, to demonstrate the analytical utility of this method, a preliminary study was undertaken by determining the amount of ML I spiked into distilled water by $10 \mu \mathrm{g} / \mathrm{mL}$. $100 \mu \mathrm{L}$ of $10 \mu \mathrm{g} / \mathrm{mL}$ ML I aqueous solution was used instead of $100 \mu \mathrm{L}$ of the standards, the percent inlibition was observed and. finally, the concentration of ML I was deternined by the calibration curve obtained. The experintent was repeated five times. The results show that the mean value is $10.03 \mu \mathrm{g} / \mathrm{nL}$ and the SD is 0.18 . The difference between the spiked value and the mean value is $0.03 \mu \mathrm{g} / \mathrm{mL}$. with a relative error of $0.3 \%$. Thus. this method has good reproducibility for trace analy sis. such as $10 \mu \mathrm{g} / \mathrm{mL}$ of ML I with $1.6 \%$ of RSD.
Acknowledgement. This work was supported by Korea Research Foundation Grant (KRF-2002-015-CP0258).

\section{References}

1. Jaggy: C.: Musielshi. H.: Urech. K.: Schaller. G. Arzheim. -Forsch. Drug Res. 1995.45 .905$.

2. Franz. H. Adhances in Lectin Research; Franz, H. Ed.: Verlag Gesundheit and Springer Verlag: Berlin. 1991; Vol. 4. p 33.

3. Hajto. T.: Hostanskia. K.: Fornalski. M.: Kirsch, A. Dtsch. Zscht Onkol. 1991.23.1.

4. Stein. G. M.: Edlund. U.: Pfuller. U.: Bussing. A.: Schietzel. M. Anticancer Res. 1999.19.3907.

5. Eck. J.; Langer, M:; Mockel. B.; Wilthohn, K.; Zinke. H.: Lentzen, H. Eur. J. Biochent 1999. 265,788.

6. Eschenburg. S.: Krauspenhaar, R.: Mikhailov, A.; Stoeva. S. Betzel. C.: Voelter. W. Biochem. Bioplys. Res. Comm 1998. 247. 367.

7. Soler. M. H.: Stoeva. S.: Voelter. W. Biochem. Bioplys. Res. Conmt 1998. 246,596.

8. Bussing. A.: Multani. A. S.: Pathak, S.; Pfuller, U.; Schietzel, M. Cancer Letters 1998. 130,57.

9. Zisha. P.: Franz. H.: In Lectins: Bog-Hansen. T. C.: Breboriowicz. J.. Eds: Walter de Gruyter: Berlin-New York. 1985: Vol. 4. $\mathrm{p} 473$.

10. Vang. O; Pil Larsen. K.; Bog-Hansen. T. C.: In Lectins: BogHansen. T. C.; van Driesche, E., Eds.: Walter de Gruyter: BerlinNew York, 1986; Vol. 5, p 637.

11. The Inmunoassay Handhook. $2^{\text {nd }}$ ed.: David. W. Ed.: Nature Publishing group: U.K. 2001.

12. Kim. M. T.: Kim. H. T.: Kim. J. M.: Kim. S. H.: Cha. G. S. Anat. Biochem. 1995. 231. 400 .

13. Shim. Y. N. Paeng, I. R. Bull. Korew Chent. Soc. 2003. 24. 70.

14. Choi. M. H: Kim, M. W.: Cho, H. C.: Kim. M. S.: Lee, E. A.; Paeng. I. R.: Cha. G. S. Bull. Korean Chem. Soc, 2001. 22. 417.

15. Kjellstrom. T. L.: Bachas. L. G. Anal. Chem. 1989.61. 1728.

16. Cha. G. S.: Meyerhoff. M. E. Anat Chim Acta 1988. 208.31.

17. Bachas. L. G.: Meyerhoff. M. E. Anal. Biochem. 1986, 156. 223.

18. Beuth. J: Ko. H. L.; Tunggal. L.: Geisel, J.: Pulverer, G. Arzneint.Forsch. Drug Res. 1993. 13,2. 